\title{
MODEL BASED SYSTEMS ENGINEERING INTRODUCTION WITHIN INDUSTRIAL ENGINEERING CURRICULUM
}

\author{
Pierre DAVID'1, Eric BLANCO² Sebastien REVOL ${ }^{2}$, Florian NOYRIT² and Michel \\ COATRINE ${ }^{3}$ \\ ${ }^{1}$ Univ. Grenoble Alpes, CNRS, G-SCOP 38000 Grenoble, France \\ ${ }^{2}$ CEA LIST, Executable Language Engineering and Optimization Laboratory, Point Courrier \\ 174, Gif-sur-Yvette, 91191 France \\ ${ }^{3}$ Schneider Electric
}

\begin{abstract}
Systems Engineering (SE) has been initially developed to manage large complex system development in the defence or aerospace industry. As the complexity of product increases, the product development approaches evolved accordingly. Complex architectures have to be developed including multiple disciplines of engineering (software, electronics, mechanics etc..). Automotive industry moved to SE about 15 years ago, medical devices industry had been implementing such models to meet accreditation agencies requirements and general industry is now transforming their processes to address complex solution that add value to their customers. Moreover, some companies started to apply Model Based System Engineering (MBSE) in their processes to validate requirements and architectures. MBSE tools have been progressing for a decade, yet MBSE value proposition is not fully agreed within industry and adoption remains slow. To face these challenges, it seems important to introduce industrial engineering students to a complete view of SE including the benefits, the challenges and the technics of MBSE.

In this paper, we discuss the question of competencies in Systems Engineering to address within the Industrial Engineering curriculum of Grenoble school of Industrial Engineering and Management. Since many dimensions are already addressed within the curriculum, modifications of some courses have been implemented to introduce SE and MBSE. A mapping with Graduate Reference Curriculum for Systems Engineering students' outcomes is presented and pedagogical choices using projects and case studies are discussed. Lessons learnt from experience with students learning outcomes are given.
\end{abstract}

Keywords: Systems engineering, model-based systems engineering, industrial engineering

\section{INTRODUCTION}

Industrial Engineering and Management (IEM) Curriculum is dedicated to train engineers to handle complex industrial problems with multiple dimensions. Design and operations management of complex systems and project are core activities of industrial engineers. The curriculum has been designed to prepare students to cope with complex project management. It is including sciences, technology and management. Thus Systems Engineering (SE) could be considered as a critical part of the curriculum. If SE approach was initially deployed in military, medical, aerospace and automotive industries, it spreads today in all sectors and need to be considered in IEM curriculum.

The Graduate Reference Curriculum for Systems Engineering (GRCSE) initiative [1] presents the core competencies to be taught in a SE educational programme. Six knowledge areas to be covered in a SE educational programme are defined and expected students' outcomes are presented. The proposal is very complete to span the whole topics of SE but less detailed regarding MBSE. "Industrial Engineering" is mentioned as a related topic. Since digitalisation of product and industry is increasing, with Industry 4.0 revolution, SE and Model Based Systems Engineering (MBSE) are critical approaches to design and operate what is now referred as complex Cyber-Physical-Social Systems [2]. In a recent report from NASA, experts raise the expectations of Model-Based methods into an organisation and identified requirements to foster infusion [3]. But when implemented in industry, MBSE expectations are not always met and MBSE use stays behind objectives [6]. Tools maturity remains a difficulty identified by 
professionals as mentioned in the survey of Huldt and Stenius [4]. But workforce knowledge, skills and abilities are viewed as prerequisite to start spreading within organisations. One main challenge to MBSE adoption is overcoming organisational and cultural hurdles. It can be mitigated according to authors through providing education and training. According to Huldt and Stenius [4] survey in the MBSE professional community, to work on training and education is the second preferred choice to improve MBSE approaches in industry. A recent study in France had also illustrated practices and expectations for MBSE in the verification and validation processes in companies and identified education needs [5]. But what major principles should be introduced in the curriculum about SE and MBSE particularly in the core of an IEM curriculum? This paper will present an answer to this question for an IEM curriculum in France. The next section presents some experiences from literature and GRCSE graduate outcomes as inspiration. Section 3 gives an overview directly related to SE in the school's curriculum and details specific new courses that introduce MBSE. Section 4 presents feedbacks from these experiences and sketches perspectives.

\section{SE AND MBSE PRACTICES IN ENGINEERING EDUCATION}

Apart from fully dedicated programmes, a lot of teachings are still based on traditional document-centric SE practices [6] [7]. Nevertheless, some experiences of introduction of MBSE in curriculum had been shared in the community. These elements are essentially concerning curriculum in mechatronics since complexity of embedded systems requires to implement this new Knowledge, Skills and Abilities [3], [9], [10]. Beyond knowledge about formalism and tools, soft skills are critical in SE. Most of the presented experiences are using project-based learning using Cyber Physical System or mechatronic applications to support learning process. Teamwork is proposed to develop soft skills. Some courses propose mix of regular teaching and exercise and project [9], some are fully project-based [10]. Stevens [11] use an original approach, using case studies writing in SE education. Most of authors claim that experiential learning [12] pedagogical approach seems critical to learn SE and MBSE. But most of the experiences are referring to a specific course content and do not refer to the whole curriculum and beyond pedagogical approach content specification to cover SE and MBSE is also under questions. The GRCSE initiative [1] is a great insight as it proposes elements to qualify SE programmes. The GRCSE proposes to analyse curriculums with four major categories of programme outcomes. These outcomes correspond to what students are expected to know and do by the time of graduation. Each category has three or four outcomes:

- $\quad$ SE Concepts: Foundation (SECF) Concentration (SECC) Topic Depth (SECTD)

- SE Role: application Domain (SERAD), Specialty (SERS), Related disciplines (SERRD), Software in Systems (SERSS)

- SE Practice: Requirement Reconciliation (SEPraRR), Problem/Solution Evaluation (SEPraPSE), Realism (SEPraR)

- $\quad$ SE Professionalism: Professional Development (SEProPD), Teamwork (SEProT), Ethics (SEProE) These categories are used to classify contribution of courses within our global curriculum (table 1).

\section{INDUSTRIAL ENGINEERING CURRICULUM TRANSFORMATIONS}

\subsection{Overview of SE and MBSE in IEM curriculum}

Organisation of Engineering studies in France apply EU Bologna standard (3-5-8) but still education institutions called "Grandes Ecole's" enrol students after two years on higher education. Only $20 \%$ of the students had an introduction to SE before arriving at the engineering school in third year of bachelor. Students who enter the curriculum can come from different programmes where mainly basic sciences is studied. The third year of bachelor programme is unique for all students. Then they can choose one of the two different tracks proposed in the engineering master's degree: One focused on product design and development and the second oriented to supply chain management.

A general view of curriculum that concerns Systems Engineering in the IEM School is summarised in table 1 . The percentage presented in the table represents a ratio of students that can follow the course over the number of students in a year (120). $100 \%$ means that the course is a core course for all students. Since personalisation of the curriculum is the rule in the school, students can choose multiple specialisation courses. 
Two courses are fully dedicated to SE and addressing MBSE. One is proposed as a core course in third year of bachelor (L3) and one as an elective in first year of master's (M1). They are in bold in the table 1. Other courses introduce some key concepts of SE and MBSE within their content while they are not dedicated to. For example, product representation course addresses information modelling and management in product development. It introduces students to SysML modelling and MBSE. The course of advanced design methods introduces architecture and risk modelling and definition. Part of this course is to train students to design product architecture using SysML models and DSM matrix. Project management is mainly treated in specific courses not fully dedicated to SE. Project-based learning also requires project management concepts application. Other courses like cost modelling, project accountancy or sociology and organisation sciences courses that address human factors in industry are not presented since they are not referring explicitly to SE. This demonstrates that students who are willing to specialise in SE can follow 43,5 ECTS credits over 150 credits of courses proposed in the curriculum of IEM School. This count excludes 30 ECTS credits of internship and final project thesis that can be dedicated to SE if students want to.

Table 1. Overview of the courses of the curriculum related to SE

\begin{tabular}{|l|c|c|l|}
\hline \multicolumn{1}{|c|}{ Course Title } & ECTS & $\begin{array}{c}\% \text { of students } \\
\text { concerned }\end{array}$ & Corresponding GRSCE outcomes \\
\hline Bachelor year 1 and 2 - L1 (Out of IEM School curriculum) \\
\hline Introduction to SysML & 1 & $20 \%$ & \\
\hline IEM School - Third Year Bachelor & $\mathbf{6}$ & $\mathbf{1 0 0} \%$ & SECF; SERRD, SEPraRR, SEProT \\
\hline Introduction to SE & 3 & $20 \%$ & SEProT, SERAD \\
\hline Project Management technics & 1.5 & $100 \%$ & SECD, SERRD \\
\hline Bachelor project & \multicolumn{3}{|c|}{ IEM School - Master Programme } \\
\hline Product Representation & 6 & $50 \%$ & SECC, SERS \\
\hline Advanced Design Methods & 6 & $50 \%$ & SERS, SECC \\
\hline Systems Engineering & $\mathbf{3}$ & $\mathbf{2 0 \%}$ & SEPraPSE, SECC, SEProT \\
\hline $\begin{array}{l}\text { Modelling and Optimisation } \\
\text { in Product Development }\end{array}$ & 6 & $15 \%$ & SERAD \\
\hline $\begin{array}{l}\text { International Project } \\
\text { Management }\end{array}$ & 6 & $15 \%$ & SECD, SERS, SERRD \\
\hline $\begin{array}{l}\text { Industrial Information } \\
\text { Systems }\end{array}$ & 6 & $15 \%$ & SERRD \\
\hline $\begin{array}{l}\text { iDesigner : Tackling } \\
\text { Complexity by Integration }\end{array}$ & 6 & $15 \%$ & SECC \\
\hline $\begin{array}{l}\text { Knowledge Integration and } \\
\text { Collaboration in Design }\end{array}$ & 6 & $15 \%$ & SERRD, SEProT \\
\hline
\end{tabular}

In the next sub-sections, we focus on the two MBSE dedicated courses dedicated to modelling language acquisition from requirement to architecture phase.

\subsection{Third year Bachelor: Core course Introduction to Systems Engineering}

This course represents 6 ECTS and is mandatory for all students of third year of bachelor. The course consists of lectures, exercises and a development project. 120 students are concerned. Students have to specify, design and realise a prototype of a connected object. They work during projects in groups of three. At the end of the project, Students have to demonstrate the prototyped system meets the requirements they have defined. SysML language is used for operational scenario modelling, context analysis and architectures (functional \& physical) definition.

The object to be designed is first introduced as part of a larger system: a video conferencing system of an amphitheatre. First exercises start with the complex system analysis. The course introduces MBSE through SysML language. Our approach is close to SysKIT 2.0 approach [9]. Not all diagrams are used in the case study. Students are expected to acquire diagram formalism on their own and dedicated resources are provided online. Lectures are mainly presenting the process of engineering from requirements elicitation to architecture definition. In class, exercise deals with the process and the use of diagram. System context and systems requirements are defined using Use Cases, context diagrams 
and requirements elicitation. Functional architecture is represented through Activity Diagram and System description is given through Internal Block Diagram. This description leads students to derive requirements of the component to be designed during project: an automatic camera mount to track the speaker. The second step is organised as courses in industrial informatics and mechanical design that are also delivered with application exercise to support the project phase. Third step is project-based during which students have to develop and prototype the camera mount. Arduino, motors and multiple sensors are given for product design and prototyping. Students also use the fablab of the school and CAD software to design and materialised solution. Deliverables are asked using SysML models, CAD Models and audit are done with teachers as project evaluations. A short video should demonstrate functionalities of the prototype. One major pedagogical concern was about introducing or not a SysML modelling tool. The choice has been made to only introduce the language since the modelling tool appropriation would have been too heavy. The modelling tool is then introduced in the master's programme.

\subsection{Master 1: Elective course on Systems Engineering}

This optional course is held in the first year of the master's programme. The course is design to lead students to master MBSE and SE project approach. The course has been created in collaboration with SE experts of Schneider Electric and two researchers from a public research centre who are experts in SysML modelling tool. The course is delivered by these professionals.

This course focuses on the technical activities of Systems Engineering, Project Management techniques are out of scope. The course starts by illustrating changes that are expected in people's behaviour to deploy SE (being conscious of human cognitive biases, deploying active listening of stakeholders, empathy ...). Then, a second part deals with the development processes, the tasks that are performed and the deliverables that shall be produced. This part finishes with a presentation of various modelling and simulation techniques. The third part addresses critical issues for SE deployment and transformation of the company. It also presents the way SE experts who contribute to professional networks (INCOSE) envision the future with a new approach (System Thinking). Experts share with students' probable evolutions in the coming ten or twenty years

The fourth part of the course is dedicated to MBSE using an eclipse based modelling environment Papyrus [13]. Lecturers are researchers involved in the community of Papyrus development. SysML language is presented and modelling principles are illustrated thanks to a guided case study. To help students beginning with a deep use of SysML concepts, a usage methodology is given. The kind of diagram and modelling constructs to be used at each step of a classic SE development project are defined. This can be seen somehow as a bias in SysML presentation, but we considered it mandatory to obtain an efficient use of SysML in a limited time.

All along the course, students are committed in an industrial case study proposing to design a Cyber Physical System (CPS): an Autonomous Carrying System to be used in a warehouse. The case study has been developed to lead students to the specification of the system namely using Papyrus models. Customer expectations had been built with an industrial partner from a logistic company. To lead students within project, deliverables had been specified with inspiration from the framework proposed by the French chapter of INCOSE (AFIS) robotic challenge (RobAFIS). Deliverable milestones are given for each step and teams of five students are proposed. Five deliverables are required:

1. Mission and stakeholder analysis

2. System requirement definition

3. System architecture of the system (sub system and technological components)

4. Justification document

5. Integration verification and validation plan

This case study project gives the opportunity to students to experience many aspects of SE projects. We can mention for instance: the difficulty to develop unambiguous specification, the challenge of tracing decision and information, the iterative nature of the specification work. They struggle to find the right focus and to choose the right level of detail. The content and pedagogy of the course develop different GRCSE Outcomes; SE practice Problem/solution Evaluation, SE Concept Concentration and SE Professionalism Teamwork according to appendix D of GRSEV1.1 [1-table23p96]. 


\section{LESSONS LEARNED}

The project of the bachelor course (specify, design and prototype a connected object) is very engaging for students and generates many outcomes in domain application. Students face many problems and the project acts as a learning crash-test highlighting multiple SE critical issues. It contributes to system thinking learning. The project allows students to experience heterogeneity of domain application product data and their relations: CAD model for mechanical part and manufacturing, Software and wire diagram with Arduino. They face the necessity of System level Models like structural architecture (SysML Ibd diagrams) to relate the domain specific models.

Yet one difficulty is the understanding of shift between a document-centric approach and a Model Based Approach. As soon as we introduce SysML language only as representations, diagrams appear as separate documents and not all students understand links between them in the unity of a model. So that product representation continues to be viewed as a set of documents and not as a unified model. This learning outcome requires the use of a modelling tool.

A second feedback is that when students engage themselves in project realisation, they face many difficulties and challenges in the technical activities of design and realisation. Sometimes they consider formalisation, models and documentation more as school deliverables than critical and practical tools to perform the tasks. Thus, the meaning of modelling remain low in the students learning. Live Audit of deliverable made by teacher with the teams tend to lead students in the reflexive observation and conceptualisation required for experiential learning [12].

A third feedback we can formulate is on the technical aspect that underlies a MBSE approach. When considering using models from the need analysis to the architecting process, SysML could be taught has a substitute for IDEF-0, functional analysis or APTE method. It is independently presented from its software engineering background (UML). We were first motivated by hiding the Object-Oriented philosophy underlying SysML to concentrate on the SE expressiveness of the drawings. This led to many misunderstandings and frustrations when transiting to a modelling software. The SysML presentation course at the master's 1 level now starts with basics of Object-Oriented modelling (Inheritance, instantiation, cross diagrams links ...).

The full potential of MBSE is difficult to highlight and demonstrate in a single course. Unfortunately, the expressivity and richness of the tools tend to hamper the understanding of MBSE benefits. Even with simple use cases, this richness overwhelms students, leaving them somewhat doubtful about the effectiveness of MBSE. Nevertheless, in the context of this experimental course, we managed to demonstrate the use of model-based simulation of a simple system (at the cost of providing templates models to hide most of the underlying modelling complexity) in a digital twin execution approach. Even though the course introduces theoretically all the benefits of MBSE, illustrating them in practice is challenging. For instance, traceability, documentation generation, trade-off analysis, safety and security analysis ... can hardly be integrated in a pedagogical and easy to access framework in the context of a single course. A further direction to improve the education may be to go beyond the theoretical introduction of MBSE concepts in the various courses of the curriculum by applying the MBSE techniques in practice when it is relevant. This would help students to understand the benefits of MBSE in a more practical way.

\section{CONCLUSIONS}

To introduce SE and MBSE in the IEM curriculum too new courses had been introduced to complement existing training. One had been restructured from two domain courses. It introduces students to system thinking and associate's systems modelling language. It is a compulsory course for all students based on experiential learning. Second course is optional and offers students to deepen SE concepts and MBSE using Papyrus modelling Environment. This approach covers some students' outcomes defined by GRCSE. Teaching Systems Engineering is specific in the sense that it cannot be considered independently from other engineering disciplines. Nevertheless, it has its own specific approach and way of thinking, with a specific vocabulary that requires focused courses. This generates tensions and difficulties to move from the technical disciplines point of view and vocabulary to the more "generic" $\mathrm{SE}$ one in the curriculum.

A workshop organised by AFIS (French Chapter of INCOSE), held at Grenoble-INP IEM school in 2018, regrouped 29 attendees on the topic of SE education. Professionals from industry emphases that beyond the technical knowledge, the main difficulties are on pushing employee's soft skills. The top 5 behavioural competencies emerging from panel were: communication skills (listening, animation, 
presenting), ability to interface domains, having a wide view on problems, curiosity and empathy. SE Education should include these outcomes within the teaching design. A next step would be to associate students with different technical background. Even if the course welcome international students, all of them still have an industrial engineering background. It would be fruitful to welcome students from different engineering disciplines like computer science or electronics backgrounds.

This experiment also demonstrated the need for a better coupling in the toolchains of MBSE. An effort seems unavoidable to provide education versions of the tooling (subset of the modelling language expressivity, and simplified user interfaces, tool assisted methodology...). In addition, preconfigured toolchains and template modelling artefacts are key success factors in teaching MBSE.

\section{ACKNOWLEDGEMENT}

This pedagogical transformation has been funded by training programme of IDEX University Grenoble Alpes Ref ANR-15-IDEX-0002

\section{REFERENCES}

[1] BKCASE, "Graduate Reference Curriculum in Systems Engineering (GRCSE)," Body of Knowledge and Curriculum to Advance Systems Engineering (BKCASE ${ }^{T M}$ ) project. 2015.

[2] Zhang J.J. et al., "Cyber-physical-social systems: The state of the art and perspectives," IEEE Trans. Comput. Soc. Syst., vol. 5, no. 3, pp. 829-840, 2018.

[3] Hale J.P. et al., "Digital Model-Based Engineering: Expectations, Prerequisites, and Challenges of Infusion," 2017.

[4] Huldt T. and Stenius I. "State-of-practice survey of model-based systems engineering," Syst. Eng., no. July, pp. 1-12, 2018.

[5] Laing C., David P., Blanco E. and Dorel X. "Questioning integration of verification in ModelBased System Engineering: an industrial Perspective.," in 12th International Conference on ModeLling, Optimisation and SIMulation - MOSIM'18, 2018.

[6] Cameron B. and Adsit D.M. "Model-Based Systems Engineering Uptake in Engineering Practice," IEEE Trans. Eng. Manag., vol. PP, pp. 1-11, 2018.

[7] Törngren M. and Herzog E. "Towards integration of CPS and systems engineering in education," Proc. 2016 Work. Embed. Cyber-Physical Syst. Educ. - WESE '16, no. January, pp. 1-5, 2016.

[8] Herzog E. and Larsson A.N. "Experience from Introducing Systems Engineering in an Academic Environment Using an Industry Training Course," in 28th annual Incose International Symposium, 2018.

[9] Matthiesen S., Schmidt S. and Moeser G. "SysKIT 2.0 - Implementation of a SysML teaching approach and observations on systems modelling by mechatronic teams," Proc. 17th Int. Conf. Eng. Prod. Des. Educ. Gt. Expect. Des. Teaching, Res. Enterp. E PDE 2015, no. September, pp. 518-523, 2015.

[10] Ugurlu S., Bougain S., Nigisher C. and Gerhard D. "Application of Model Based SystemsEngineering in Austrian Vocational Schools," in Proceedings of the 18th International Conference on Engineering and Product Design Education (E\&PDE16), 2016, no. September, pp. 089-094.

[11] Stevens J.S. "Enhancing Systems Engineering education through case study writing," in Conference on Systems Engineering Research, 2016, pp. 1-9.

[12] Kolb D.A. Experiential Learning: Experience as the Source of Learning and Development, 2nd editio. pearson education, 2014.

[13] Eclipse Foundation, "papyrus Modeling environement." [Online]. Available: http://www.eclipse.org/papyrus/. [Accessed: 06-Mar-2019]. 